\title{
Infância e adolescência na sociedade contemporânea: alguns apontamentos
}

\author{
Childhood and adolescence in the contemporary \\ society: some notes
}

Leila Maria Ferreira SALLES

\begin{abstract}
Resumo
O objetivo deste trabalho é indicar aspectos que configuram a infância e a adolescência na sociedade contemporânea, especificamente no que diz respeito à relação com o adulto. Este estudo foi desenvolvido a partir da revisão de alguns autores em psicologia e demais áreas afins, e pretende contribuir para o aprofundamento do debate sobre este tema. Na sociedade moderna, as crianças e os adolescentes inserem-se em condições sociais específicas que acentuam a sua dependência frente ao adulto. Hoje, no entanto, há uma nova forma de reconhecimento social dessas fases da vida que enfatiza um tratamento igualitário entre adulto, criança e adolescente. O desvelamento desse processo permite caracterizar os contornos que essas etapas do desenvolvimento humano vêm adquirindo atualmente e suas implicações na vida cotidiana.
\end{abstract}

Palavras-chave: adolescência; cultura; infância; subjetividade.

\begin{abstract}
This paper proposal is to indicate the childhood and adolescence issues in the contemporary society, especially in the adult-adolescent or adult-child relations. From Psychology and other related areas authors review this study was developed, and its aim is to provide this theme a better and deeper knowledge. In the modern society, children and adolescents belong to specific social conditions that support their adults' dependence. Nowadays there is a new social recognition for life phases that emphasizes an equilaterally relationship among adults, adolescents and children. This process level difference allows the description of the human development stages and their implications in the daily life.
\end{abstract}

Key words: adolescence; culture; childhood; subjectivity.

O objetivo deste artigo é indicar aspectos que acabam por configurar os contornos da infância e da adolescência na sociedade contemporânea. No contexto dessa discussão, procuraremos indicar que os critérios geracionais utilizados para descrever os indivíduos nas diferentes etapas da vida não dão mais, sozinhos, conta de abarcar toda a complexidade da sociedade atual, assim, o conceito de geração deve ser problematizado.

A criança e o adolescente, com seus modos específicos de se comportar, agir e sentir, só podem ser compreendidos a partir da relação que se estabelece

\section{$\boldsymbol{\nabla} \nabla \mathbf{v}$}

1 Departamento de Educação, Instituto de Biociências, Universidade Estadual Paulista. Av. 24 A, n.1515, Bela Vista, 13506-900, Rio Claro, SP, Brasil. E-mail: <leila@rc.unesp.br> 
entre eles e os adultos. Essa interação se institui de acordo com as condições objetivas da cultura na qual se inserem. Condições históricas, políticas e culturais diferentes produzem transformações não só na representação social da criança e do adolescente, mas também na sua interioridade. Há uma correspondência entre a concepção de infância presente em uma sociedade, as trajetórias de desenvolvimento infantil, as estratégias dos pais para cuidar de seus filhos e a organização do ambiente familiar e escolar.

O pressuposto deste estudo é que a criança e o adolescente só podem ser compreendidos no contexto da sociedade em que estão inseridos, pois indivíduo e sociedade são entrelaçados. Não há dualismo entre eles, embora a relação indivíduo e sociedade seja uma questão instigante que acaba por gerar várias polêmicas e posições controversas.

A relação indivíduo e sociedade aparece, muitas vezes, como interação entre elementos separados. Às vezes, o indivíduo é caracterizado como mera reprodução da sociedade, e, às vezes, como independente dela, como se existisse um paralelismo entre eles. A subjetividade, porém, é construída na organização social e cultural na qual os indivíduos estão inseridos, mesmo que nem sempre tenha sido entendido dessa forma, pois o privado era percebido como subjetivo, no sentido de independente da sociedade. Os elementos básicos que constituem o psiquismo - os afetos, os desejos, as emoções e a vontade - eram vistos como independentes da sociedade e como inerentes ao eu.

Os estudos buscavam identificar e determinar os elementos integrantes do psiquismo que ocorriam internamente. Postulava-se a busca do indivíduo subjetivista no qual se podia detectar uma essência humana. A identidade era vista como uma característica do indivíduo, como uma manifestação da sua subjetividade (Figueredo, 1989). A ênfase recaia no indivíduo. O fato social era percebido como exterior a ele (Durkheim, 1970).

A subjetividade, porém, só pode ser compreendida quando se tem como referência homens reais e concretos que são construídos numa dada organização social e cultural. Há um processo de apropriação da realidade pelo indivíduo de tal forma que o homem ao viver em sociedade apropria-se do social e o mundo exterior se torna interno (Leontiev, 1978; Vygotsky, 1993).

A subjetividade é construída nas circunstâncias históricas, culturais e sociais nas quais o indivíduo está inserido e também pelas experiências particulares que ele vivencia no interior dessa cultura que são irrepetíveis e determinam as idiossincrasias e a individualidade de cada um. A singularidade, aquilo que distingue os homens entre si, é determinada concretamente (Fernández Villanueva \& Torregrosa, 1984; Berger \& Luckmann, 2002).

A realidade é subjetivada pelo indivíduo na relação entre o social, que determina as significações, e o individual, dado pela elaboração e transformação dessas significações pelo indivíduo, de acordo com suas experiências pessoais. Como diz Leontiev (1978), ao apropriar-se das significações, historicamente produzidas, o indivíduo transforma-as de acordo com o seu psiquismo individual. As significações subjetivadas tornam-se parte de seu pensar cotidiano. Esses significados, produzidos pela sociedade, adquirem um sentido pessoal, se individualizam, se subjetivam e se transformam através de atividades e pensamentos de indivíduos concretos e retornam ao mundo exterior já reelaborados pelos indivíduos.

A cultura dá os referenciais lingüísticos, os signos e as maneiras de manifestação da subjetividade. Mudanças na cultura têm implicações na forma como a subjetividade é construída. Há um processo de apropriação da realidade pelo indivíduo. O psiquismo se constrói com as experiências, os conhecimentos, os valores e as informações transmitidos pela tradição, pela comunicação, pela mídia, pela educação e pela ciência (Leontiev, 1978; Vygotsky, 1993).

A subjetividade só pode ser compreendida como produto das relações e mediações sociais e o psiquismo é mediatizado pelas relações sociais. $\mathrm{O}$ psiquismo é, assim, mediato e não imediato. A sociedade impõe ao indivíduo a forma pela qual as subjetividades são construídas.

Os modos ou os processos de subjetivação indicam a forma pela qual os homens se apropriam da sociedade. Assim, é possível verificar a transformação e a historicidade da subjetividade, pois cada época histórica tem uma forma própria de sentir, trabalhar, desejar e viver. Ou, como diz Machado (2002, p.214),"o 
que acreditamos ser nossa personalidade, nosso mais intenso desejo, são expressões em nós da história de nossa época".

A história de vida, embora seja singular, não é um processo interior independente da sociedade, pois o social constitui o subjetivo. A sociedade contemporânea caracterizada pela predominância das tecnologias da informação, pela realidade virtual, pela interação mediada pela máquina, pelo questionamento da ascendência da cultura superior, onde o conhecimento científico é só mais um tipo de conhecimento, determina modos específicos de subjetivação que são próprios dessa época (Sennett, 1975; Tajfel, 1984; Giddens, 2002; Hall, 2002).

A identidade da criança e do adolescente é construída hoje numa cultura caracterizada pela existência de uma indústria da informação, de bens culturais, de lazer e de consumo onde a ênfase está no presente, na velocidade, no cotidiano, no aqui e no agora, e na busca do prazer imediato. A subjetividade é, então, construída no comigo mesmo, na relação com o outro e num tempo e num espaço social específicos.

Mesmo que as concepções anteriores de crianças e adolescentes não possam ser descartadas porque continuam respondendo a questões presentes nessa área de estudo, é necessário problematizá-las, já que essas concepções não permitem mais captar toda a complexidade do significado da infância e da adolescência hoje. A sociedade atual acaba por impor uma revisão da distinção entre criança, adolescente e adulto até agora dominante. Nesse sentido é que este texto busca apontar para a necessidade de repensar os parâmetros que definem a infância e a adolescência na sociedade atual.

\section{Infância e adolescência como etapas da vida}

No final do século XVIII e início do XIX, a percepção que até então se tinha da criança foi gradualmente se modificando e a concepção de infância como uma etapa distinta da vida se consolidou na sociedade. Essa percepção, de acordo com Ariès (1986), é concomitante à constituição da família nuclear, do estado nação e da nova organização do trabalho produtivo.

O conceito de infância e adolescência é uma invenção própria da sociedade industrial, ligado às leis trabalhistas e ao sistema educacional que torna o jovem dependente dos pais. Como diz Ariès (1986), a especificidade da adolescência foi reconhecida e emergiu com a escolarização, que supõe a separação entre seres adultos e seres em formação, com a família burguesa que separa o espaço familiar do exterior e com a progressiva exclusão da criança do mundo do trabalho. Esse processo que se iniciou nas classes sociais mais abastadas estendeu-se para toda a sociedade e se impôs como um modelo que atingiu toda a organização social.

A criança foi, então, excluída do mundo do trabalho e de responsabilidades; foi separada do adulto, não participando mais de atividades nas quais até então a sua presença era usual (Ariès,1986). A criança adquiriu um status de pura, assexuada e inocente (Coll, 1995).

A distinção criança e adulto fez com que a adolescência começasse a ser percebida como um período à parte do desenvolvimento humano. Conforme Ariès (1986), por volta de 1890 começou a se firmar o interesse pela adolescência, que se torna tema literário e preocupação de moralistas e políticos. Gradualmente, a adolescência como uma fase da vida vai se consolidando e se torna um fenômeno universal, com repercussões pessoais e sociais inquestionáveis. A adolescência passa a ser caracterizada como um emaranhado de fatores de ordem individual, por estar associada à maturidade biológica, e de ordem histórica e social, por estar relacionada às condições específicas da cultura na qual o adolescente está inserido.

Na sociedade moderna, com suas condições materiais e simbólicas específicas, a criança, o adolescente e o jovem adquiriram um status de dependentes, não responsáveis jurídica, política e emocionalmente. A criança vai à escola, brinca, mora com a família, é feliz e não tem responsabilidades (Castro,1998; Leite, 2000). Socialmente, fundamenta-se a concepção de que as crianças e os adolescentes devem ser disciplinados para se tornarem adultos.

A criança deve ser submetida à ordem pela internalização dos costumes, das normas, dos valores sociais e dos significados simbólicos estabelecidos socialmente (Durkheim, 1970). A criança deve ser socializada, o que assegura a transmissão da cultura e garante a continuidade da sociedade. Junto com a 
família, a escola se estabelece como uma agência socializadora de transmissão de significado e de cultura, ficando também a seu encargo os processos disciplinadores, educativos e de guarda das crianças (Lasch, 1991).

A emergência da noção de criança como um sujeito, com especificidades próprias, acarreta o surgimento de políticas sociais e educacionais que visam orientar a família sobre como criar filhos e corrigir os desvios. Segundo Lasch (1991), a infância e a adolescência tornam-se um objeto de estudo dos especialistas.

Os conhecimentos e saberes médicos, psicológicos, pedagógicos, sociológicos etc estruturam a reflexão sobre a infância e sobre a adolescência. Na psicologia do desenvolvimento, campo de estudo da área psicológica que começa a se consolidar por volta de 1900, as crianças e os adolescentes são concebidos como imaturos, não desenvolvidos e devem se desenvolver para atingir a maturidade 2 . As pesquisas na área são explicativas, procurando entender o porquê desses comportamentos durante essas fases da vida, e normativas, descrevendo padrões de comportamento nas diferentes idades.

As teorias que procuram explicar a adolescência, no enfoque psicológico, apontam divergências entre os autores quanto à relevância da maturação e da aprendizagem no processo do desenvolvimento humano, com ênfase ora em um aspecto ora em outro, ou postulando a interação entre eles ${ }^{3}$. Os resultados das pesquisas normativas apontam que, em certas áreas, o adolescente se comporta como adulto, e, em outras, como criança (Gallatin, 1978). Isso corrobora a definição de adolescência segundo a qual o adolescente está vivendo uma etapa de vida considerada de transição entre o ser criança e o vir a ser adulto.

O saber psicológico estabelece quais são as normas de conduta previstas para uma determinada faixa etária, o que é normal e o que é anormal (Coll, 1995). A criança ao se desenvolver passa dos estágios mais simples aos mais complexos, chegando à idade adulta. As teorias na área afirmam que o desenvolvi-

$\mathbf{\nabla} \mathbf{\nabla}$ mento é ordenado para uma complexidade crescente. O desenvolvimento é definido como seqüenciado e vai do pré-social ao social, ou do social ao individual, e do pré-lógico ao lógico. O vir a ser está ordenado, hierarquizado e previsto (Wallon, 1968; Piaget, 1976; Vygotsky, 1993).

As mudanças que ocorrem na fase de transição de criança para adolescente e de jovem para a idade adulta, isto é, os estágios da vida, se consolidam como objeto de estudo. Os diferentes estágios encontrados nessa transição, que vai da dependência infantil à aquisição da autonomia, as influências dos estilos parentais no modo como as crianças e adolescentes e jovens se comportam, as maneiras pelas quais os professores impõem limites, as diferenças de socialização de acordo com as classes sociais, as instituições criadas para receberem a criança, como as creches, os jardins de infância e a escola e as formas de lazer, são investigados e analisados (Fernández Villanueva, 1985; Simmel, 1986).

Desde os anos 20, principalmente nos EUA, os estudos sobre socialização adquirem importância como objeto de investigação na área psicológica. Nesses estudos, são analisadas as relações entre as gerações e as práticas educativas vigentes em diferentes países. Examinam-se as relações pais e filhos, as mudanças de atitude do adulto frente à criança, o modo como o adulto reage frente aos comportamentos de independência e autonomia das crianças e dos adolescentes e as diferentes formas de imposição da disciplina paterna (Fernández Villanueva, 1985; Montandon, 2001).

É inerente à concepção de desenvolvimento a idéia de que a criança se prepara para ser adulto. A criança e o adolescente são submetidos às ações das agências socializadoras que os preparam para atingirem a razão e a maturidade. Dessa forma, as etapas da vida se hierarquizam e o desenvolvimento adquire uma meta: tornar-se adulto, pois só o adulto sabe conduzir sua vida.

A adolescência se configura, então, como um período de experimentação de valores, de papéis

considerado o fundador dos estudos sobre a adolescência. Seus escritos são, basicamente, da primeira década do século XX

3 As teorias formuladas por Anna Freud, Erikson e Aberastury e Knobel, de origem psicanalítica, estão entre as mais freqüentemente citadas em livros e teses que tratam da temática da adolescência. Os trabalhos de Anna Freud foram escritos a partir do final da década de 20, os de Erikson, a partir das décadas de 40 e 50, e os de Aberastury e Knobel, a partir dos anos 70 (Erikson, 1976). 
sociais e de identidades e pela ambigüidade entre ser criança e ser adulto. O jovem está apto para a procriação, para a produção social e para o trabalho. Porém, a ambivalência da sociedade quanto à possibilidade de efetivação dessas aptidões faz com que ele adquira um status intermediário e provisório, e passe a ser tratado de forma ambivalente: como criança e como adulto (Aberastury 1980; Abramo, 1994).

Assim, como diz Abramo (1994), o que define a adolescência e a juventude é a transitoriedade. Ser menor, não adulto, define uma condição social e psicológica e torna as gerações interdependentes e hierarquizadas. Mesmo que haja uma pluralidade de infâncias, adolescências e juventudes em função das diferenças concretas das condições de vida existentes na sociedade, a criança e o jovem são tutelados pelo adulto, já que são desiguais a eles.

As idades da vida são, então, separadas. Na sociedade moderna, a criança e o adolescente se socializam para se integrarem e se adaptarem à sociedade. Esse processo de socialização implica uma longa educação, com metas a longo prazo. Ao final do mesmo, a criança deve chegar ao autocontrole, à autonomia e à independência que são características atribuídas ao adulto. A conduta de criança e de jovem devem ser superadas.

No entanto, parece-nos que as colocações feitas acima, nas quais se postula essa separação entre crianças, adolescentes e adultos, devem ser problematizadas em função das mudanças verificadas na sociedade atual.

\section{A infância e a adolescência na sociedade con- temporânea}

A interação entre crianças, adolescentes e adultos, como dito antes, se institui de acordo com as condições objetivas da cultura na qual se inserem. Assim, mudanças socioculturais tendem a promover modificações nas formas pelas quais a infância e a adolescência são percebidas na sociedade contemporânea. Hoje, parece-nos que existe uma tendência a se promover o estabelecimento de relações mais igualitárias entre adultos, crianças e adolescentes que é concomitante ao questionamento ao adultocentrismo da sociedade e ao processo de prolongamento da adolescência.
A transição da dependência infantil para a independência da vida adulta tem gerado diferentes estudos que procuram investigar como esse processo ocorre. Busca-se investigar, por exemplo, como se promovem a autonomia e a individuação das crianças e dos jovens sob um controle disciplinador, como as famílias diferem entre si quanto a esse aspecto, como e quanto elas aceitam os novos comportamentos da criança e como as mudanças que vêm ocorrendo nos papéis femininos e masculinos interferem nesse processo (Montandon, 2001).

Os estudos, principalmente aqueles efetuados a partir da década de 80, têm apontado paras as transformações que podem ser observadas nas relações pais e filhos. Segundo essas pesquisas, hoje, as relações familiares se baseiam mais no diálogo, na participação, na igualdade, na afeição e na compreensão. Os adolescentes vêem a relação com os pais como satisfatórias e tomar suas próprias decisões livremente se torna aceitável, não sendo mais uma situação conflituosa (Bosma, Jackson, Zijsling \& Zani, 1996; Kreppner, 2000; Scabini, 2000; Montandon, 2001). A transformação das relações entre pais e filhos contribui, inclusive, para que os filhos permaneçam mais tempo junto aos pais e permite o prolongamento da co-habitação em idades mais tardias (Gil Calvo, 1993; Scabini, 2000).

A tendência ao prolongamento da adolescência e da juventude na sociedade atual é apontada na literatura da área. O tempo de estudo se prolonga, a entrada no trabalho se dá mais tardiamente e a constituição da própria família é postergada (Abramo,1994; Peralva, 1997). As condições atuais implicam uma longa transição do período de adolescência e juventude para a idade adulta, fazendo com que os estilos de vida sejam experimentados.

Antes a seqüência do ciclo de vida era clara. 0 jovem primeiro estudava, ao fim da escola se empregava e daí casava. Hoje, no entanto, começa a ocorrer um processo de alongamento dessas fases, o que está, entre outros fatores, associado às dificuldades cada vez maiores de obtenção de emprego e ao prolongamento do estudo. A falta de autonomia financeira e o desemprego contribuem para que os jovens permaneçam mais tempo com os seus pais. Hoje os jovens estudam, trabalham, se especializam, adiam a saída da família de origem e a constituição da própria família. Embora esse processo seja mais acentuado nas 
camadas médias da população, há uma tendência para que se generalize para toda a sociedade.

Dadas as mudanças que vêm ocorrendo em função das transformações das condições sócio-históricas e culturais, os referenciais funcionais que demarcavam os limites entre uma idade e a outra são desorganizados. Embora os critérios cronológicos sejam ainda válidos, eles não podem ser mais entendidos como a dimensão básica para definir as idades da vida. Há uma desconexão nas diferentes dimensões que definem a entrada na vida adulta. Como diz Peralva (1997), na sociedade contemporânea está ocorrendo um processo de despadronização do ciclo de vida. As idades da vida estão "bagunçadas"e a própria idéia do que é ser tutelado se modifica.

Na modernidade, quando se acentuava o caráter preparatório do processo educativo, a diferença entre criança, adolescente, jovem e adulto estava firmemente estabelecida. Na sociedade contemporânea, caracterizada pela aceleração, pela velocidade, pelo consumo, pela satisfação imediata dos desejos, pela mudança das relações familiares e da relação criança/adolescente/adulto, o processo de socialização é distinto daquele que ocorria anteriormente.

A socialização, no sentido clássico, implica uma relação de desigualdade entre adulto e criança e um longo tempo de preparação no qual está embutida a idéia de que a criança com o ser em formação está inacabada. A socialização é sempre um processo que se dá do adulto sobre a criança. Assim, na concepção de socialização fica implícita a idéia de que é um processo de sentido único no qual a reciprocidade está excluída (Parsons, 1968; Fernández Villanueva, 1985; Castro, 1998). No entanto, os estudos realizados nas ultimas décadas com as crianças e os adolescentes nos diversos contextos da vida cotidiana e nas estruturas de poder político e econômico vêm, juntamente com as mudanças verificadas nas relações adultos/crianças e pais/filhos, questionar a idéia de socialização no sentido clássico do termo (Mead, 1973; Fernández Villanueva, 1985; Castro, 1998).

Somando-se a isso, as tecnologias da comunicação, dentre elas a tv e a internet, possibilitam que o acesso às informações se dê sem o controle dos pais. Assim, as crianças entram, por exemplo, desde cedo em contato com o sexo, com a violência, com a exploração dos conflitos íntimos, embora isso fosse um processo comum na Idade Média, pois, como foi dito anteriormente, nessa época a criança participava de todas as atividades realizadas pelos adultos, de forma que a separação entre coisas de crianças e coisas de adulto não existia (Ariès, 1986); quando da separação das idades, a criança e o adolescente foram apartados de certas atividades.

A situação atual vem, assim, se contrapor à idéia de socialização pela qual se concebia que os adultos, pais e professores em especial detinham as informações às quais as crianças poderiam ter acesso, e aquilo que deveriam saber e/ou thes era permitido fazer era controlado e estabelecido de acordo com as faixas etárias.

A produção acadêmica atual aponta que o importante é como os membros dos grupos mantêm e renegociam relações. Isto é, toda a rede de relações na qual as crianças crescem que possibilita a elas irem assimilando a cultura, os valores e as normas que vigoram na organização social na qual estão inseridas (FernándezVillanueva, 1985; Simmel, 1986; Montandon 2001). As crianças e os adolescentes são atores que interagem e reagem, negociam e redefinem a realidade social.

O exame das relações que são estabelecidas entre pares como esses dão significação à sua idade, estabelece normas e percebe a influência do gênero na construção da sua identidade, evidencia a necessidade de entender as crianças e os jovens como atores, isto é, como sujeitos e não só como sujeitadas ao processo de socialização.

Hoje, há uma maior liberdade e autonomia para os jovens e uma diminuição da autoridade e controle paternos. Os métodos autoritários e diretivos de educação são criticados. Procura-se minimizar as diferenças entre as gerações e evitar que a criança seja lembrada de sua imaturidade e dependência. Exalta-se a juventude, fazendo com que os mais velhos desejem ser jovens e que as relações entre pais e filhos se transformem, com os pais perdendo a autoridade, questionando o que fazem de errado, e a criança, o adolescente e o jovem querendo apenas ter direitos. Segundo Lasch (1991), no século XX glorifica-se a juventude e diminui-se a autoridade dos pais.

As relações de autoridade e os valores sociais e morais estão sendo questionados e revistos. De um lado, têm-se a criança e o adolescente precocemente 
seguros de como devem se comportar, e, de outro, a própria sociedade que se vê em crise de autoridade e confusa quanto aos valores morais que deve adotar, 0 que se reflete nas atitudes dos pais e dos educadores. Os pais se encontram confusos quanto às práticas educativas, não sabendo mais o certo e o errado e se devem ou não impor disciplina aos filhos. Os pais se sentem inseguros e hesitam em impor seus padrões ao mesmo tempo em que a criança e o adolescente adquirem o direito de serem respeitados nas suas exigências.

A liberalização dos costumes traz reflexos na educação dos filhos, que se torna menos rigorosa. Mudam-se as formas de dominação e a autoridade se torna democrática. Pais e professores não devem mais se impor arbitrariamente, pois a sua autoridade só merece ser vista como válida quando é justificada e justificável, ou seja, quando se conforma à razão. A demanda por especialistas provoca um controle da vida privada e leva à supervisão da educação dada às crianças. Os pais passam a hesitar sobre suas normas, sobre o que é certo e o que é errado, isto é, sobre a imposição de seus padrões morais e acabam por depositar uma confiança, que chega à dependência, nas orientações dos especialistas (Cunha, 1997; Lasch, 1991).

Paralelamente, o jovem torna-se modelo para as diferentes faixas etárias. O jovem torna-se modelo para o adulto e para a criança que, a partir de uma certa idade, em torno de dez anos, começa a se autodefinir como pré-adolescente. Difunde-se socialmente o culto à aparência, à beleza, à erotização e à necessidade de se conservar a juventude. $O$ envelhecimento tende a ser postergado.

Há, hoje, um imaginário social de juventude que leva os pais a abandonarem sua autoridade e disfarçar sua idade - "meus filhos são meus amigos". A ideologia igualitária faz com que os pais possam, agora, se apresentar como amigos, companheiros mais velhos dos filhos, se tornar colegas deles, o que se manifesta na própria aparência jovial que os pais assumem, no gosto jovem e no uso de gírias (Lasch, 1991). O modelo atual de família, segundo Lasch (1991), é o da igualdade entre os indivíduos e $\mathrm{o}$ do respeito às diferenças individuais. A importância da igualdade nas relações familiares é afirmada e essas se tornam relações entre pares e de não exigências. Não há normas rígidas de conduta e as exigências são vistas como irrealistas. A diferença é aceita e respeitada. A imposição de limites é passível de discussão.

A cultura hoje é a cultura do evitar conflitos, do suavizar o que é penoso. Substitui-se o certo e o errado por relações humanas e a "amizade se torna a nova religião" (Lasch, 1991, p.139). O amor e a disciplina não são mais colocados na mesma pessoa, poupando-se o relacionamento de conflitos. Conforme Lasch (1991), hoje, muitas das funções assumidas anteriormente pela família estão a cargo de outras instituições, de tal forma que a escola e as profissões assistenciais têm se encarregado das funções familiares, especialmente da função de socialização da criança. Segundo Lasch (1991), as profissões de assistência colocam-se contra a autoridade patriarcal, defendendo os direitos da criança e da mulher e questionando a competência dos pais.

A criança, o adolescente e o jovem adquirem o direito de serem respeitados nas suas exigências. Há, parece-nos, uma tendência a igualá-los ao adulto ou, até mesmo, em alguns aspectos, em afirmar a superioridade dessas etapas da vida frente ao adulto dada a sua familiaridade com as novas tecnologias. $\mathrm{O}$ uso do computador exemplifica uma situação na qual a superioridade da criança e do adolescente é, muitas vezes, apontada. Nas escolas, mais que a aprendizagem dos conteúdos escolares, o importante é a qualidade das relações humanas que são estabelecidas.

O direito de consumir é apontado por Castro (1998) como mais um aspecto que tende a igualar a criança, o jovem e o adulto. A relação criança e adulto é permeada pela cultura do consumo, na qual a felicidade se iguala à posse de bens materiais. Os objetos que se possui são projeções do eu e a imagem é algo que chama atenção e define posições sociais. As coisas e os objetos que possuímos demarcam relações sociais, definem o estilo pessoal, hierarquizam e discriminam grupos. Aquilo que possuímos diz quem somos, mostrando nossos gostos, interesses e estilo de vida. Mesmo que o acesso ao consumo seja restrito, pois depende da condição social, o referencial é o mesmo. A diferença está no que se consome, que varia de acordo com os diferentes grupos sociais.

Embora os objetos de consumo e o gosto se diferenciem entre as crianças e os adultos, eles estão voltados para isso. Assim, as crianças como consumidores potenciais ou reais, como diz Castro (1998), 
adquirem um "tipo de cidadania" que as torna iguais ao adulto.

O"adultocentrismo" da sociedade é denunciado (Leite, 2000). Porém, mesmo que a criança e o adulto tenham se igualado em alguns aspectos, as diferenças entre eles permanecem. Segundo Castro (1998, p.194), as relações que as crianças e adolescentes estabelecem com os outros se dão cada vez mais com os seus pares de forma que eles estão excluídos em "guetos". Hoje, crianças, jovens e adultos estão em espaços diferenciados e compartimentalizados por faixa etária. As crianças continuam se prepararando para o seu futuro e para serem adultos. A ida à escola para se preparem para o futuro permanece como um objetivo mesmo que a percepção da escola se transforme, sendo agora ressignificada como um lugar de encontrar os amigos (Salles, 1998). Crianças, adolescentes e jovens vão à escola para se preparem para o seu futuro e o tempo de escola se alonga, embora em muitos aspectos eles saibam mais que os professores.

Como se vê, parece-nos que existe uma certa ambivalência da sociedade frente à criança e ao jovem. De um lado, notamos uma tendência a se promover uma igualdade entre as faixas etárias, diluindo as fronteiras entre elas, e, por outro, a perpetuação das diferenças compartimentalizando as idades em papéis e atividades específicos. Uma possível explicação para essa ambivalência é que, como estamos vivendo na atualidade esse processo de transição, as duas tendências se sobrepõem.

\section{Considerações Finais}

As mudanças que vêm ocorrendo, dadas as transformações das condições sócio-históricas e culturais, embora não sejam lineares, acabam por promover uma "bagunça" nas idades da vida; isto é, na hierarquia de idades até então estabelecida, mesmo que essas mudanças não cheguem a atingir todas as crianças e todos os adolescentes e jovens indistintamente, pois há uma infância e uma adolescência não \. tuteladas, não protegidas e excluídas do consumo, in enquanto que há uma outra, de maior poder aquisitivo, inserida no consumo, tutelada e protegida.

Mesmo com essa ressalva, as mudanças que vêm ocorrendo desencadeiam um novo jeito de compreender a infância e a adolescência que traz implicações na forma pela qual as crianças e os adolescentes são representados e se constroem como indivíduos. Embora os critérios cronológicos sejam ainda válidos, a faixa etária não pode ser mais entendida como uma dimensão básica para definir os ciclos de vida.

Na modernidade, quando se aguçava o caráter preparatório do processo educativo, a diferença entre criança, adolescente e adulto estava firmemente estabelecida. Hoje, no entanto, há uma nova forma de reconhecimento social da infância, adolescência e juventude que tende a igualá-las à idade adulta.

O questionamento ao "adultocentrismo" da sociedade e o reconhecimento da criança como sujeito e com direitos sociais são uns dos aspectos que configuram a infância e a adolescência na sociedade atual. A criança se torna visível, alvo de ofertas de bens e serviços sociais. Porém, uma certa ambigüidade da sociedade na relação que se estabelece com as crianças, os adolescentes e jovens permanece, e eles não têm, necessariamente, seus direitos sociais reconhecidos. As crianças, os adolescentes e os jovens continuam distantes e excluídos de certas práticas sociais e políticas, permanecendo em espaços sociais próprios.

Há uma maior liberdade e autonomia para as crianças e para os jovens, mas o poder do adulto permanece. É o adulto quem assinala o espaço da criança e do jovem e essa designação se dá de acordo com as diferentes classes sociais e de acordo com o gênero, mas a crítica ao adultocentrismo pode estar levando a uma corrosão do poder do adulto, inclusive do poder paterno.

Pelo exposto acima, os critérios etários, embora importantes, mostram-se insuficientes para permitir a apreensão da infância e da adolescência na atualidade, de forma que outros parâmetros devam ser evocados.

Algumas das dimensões que caracterizam a infância e a adolescência na sociedade atual, como o prolongamento da adolescência, principalmente nas camadas médias da população, o nível de acesso ao consumo permitido às crianças e aos adolescentes, a informação não controlada, o nível de simetria das relações entre crianças, adolescentes e adultos e na relação pais e filhos, a insegurança dos pais quanto à imposição de limites, podem ser, parece-nos, parâmetros promissores para pautar essa discussão e as definições que devemos construir. 
Tudo isso, enfim, determina modos de reconhecimento da infância e da adolescência que são próprios da nossa época. É necessário, assim, reexaminar o processo de transição da infância e da adolescência para a idade adulta na sociedade contemporânea, o que nos leva a fazer uma leitura das etapas da vida conforme os contornos pelos quais se apresentam hoje para tentarmos apreendê-las em toda a sua complexidade atual.

\section{Referências}

Aberastury, A., \& Knobel. M. (1980). Adolescência normal. Porto Alegre: Artes Médicas.

Abramo, H.W. (1994). Cenas juvenis: punks e darks no espetáculo urbano. São Paulo: Scritta, Página Aberta.

Ariès, P. (1986). História social da infância e da família. Rio de Janeiro: Guanabara.

Berger, P., \& Luckmann, T.A. (2002). A construção social da realidade. Tratado de sociologia do conhecimento (22a ed.). Rio de Janeiro: Vozes.

Bosma, H., Jackson, S.E., Zijsling, D.H., \& Zani, B. (1996). Who has the final says? Decisions on adolescence behavior within the family. Journal of Adolescence, 9, 277-91.

Castro, L.R. (1998). Infância e adolescência na cultura do consumo. Rio de Janeiro: Nau.

Coll, C., Palácios, J., \& Marchesi, A. (1995). Desenvolvimento psicológico eeducação:psicologia evolutiva (v.1). Porto Alegre: Artes Médicas.

Cunha, M.V. (1997). A desqualificação da família para educar. Cadernos de Pesquisa, 102, 46-64.

Durkheim, E. (1970). Representações individuais e representações coletivas. In Sociologia e filosofia (2a ed., pp.15-49). Rio de Janeiro: Forense Universitária.

Erikson, E. (1976). Identidade, juventude ecrise. Rio de Janeiro: Zahar.

Fernandez Villanueva, C. (1985). Socialización infantily clase social. Madrid: Universidad Complutense.

Figueredo, L.C. (1989). Revisitando as psicologias. Rio de Janeiro: Vozes.

Freud, A. (1969). La adolescencia encuanto pertubación del desarrollo. In L. Caplan (Org.). El desarrollo del adolescente. Buenos Aires: Paidós.

Gallatin, J. (1978). Adolescência e Individualidade: uma abordagem conceitual da psicologia da adolescência. São Paulo: Harper \& Row do Brasil.

Giddens, A. (2002). Modernidade eidentidade. Rio de Janeiro: Zahar.

Gil Calvo, E. (2002). Emancipación tardia y estrategia familiar. Madrid: Injuve.
Hall, S. (2002). A identidade cultural na pós-modernidade (7a. ed.). Rio de Janeiro: DP\&A.

Kreppner, K. (2000). The child and the family: interdependence in developmental pathways. Psicologia: Teoria e Pesquisa, 16 (1), 11-22.

Lasch, C. (1991). Refúgio num mundo sem coração. A família: santuário ou instituição sitiada? (p.139). Rio de Janeiro: Paze Terra.

Leite, C.D.P. (2000). Mosaico: os múltiplos olhares da/na sala de aula - questões para repensar o trabalho da /na escola. In C. Leite, L. Salles \& M.B. Oliveira (Orgs.). Educação, psicologia e contemporaneidade: novas formas de olhar a escola (pp.11-28). São Paulo: Cabral.

Leontiev, A.N. (1978). Actividad, conciencia y personalidad. Buenos Aires: Ediciones Ciências del Hombre.

Machado, L.D. (2002). Subjetividades contemporâneas. In L.D. Machado, M.C.C Lavrador \& M.E.B. Barros. Texturas de psicologia: subjetividade e política contemporânea (pp.211-29). São Paulo: Casa do Psicólogo.

Mead, H.G. (1973). Espíritu, persona y sociedad. Buenos Aires: Piados.

Motandon, C. (2001). Sociologia da infância: balanço dos trabalhos em língua inglesa. Cadernos de Pesquisa, 112, 33-60.

Parsons, T. (1968). Uma visão geral. In A sociologia americana: perspectivas, problemas, métodos. São Paulo: Cultrix.

Peralva, A.T. (1997). O jovem como modelo cultural. Juventude e Contemporaneidade. Revista Brasileira de Educação, 5/6, 15-24.

Piaget, J. (1976). Da lógica da criança à lógica do adolescente. São Paulo: Pioneira.

Salles, L.M.F. (1998). Adolescência, escola e cotidiano: um discurso contrastanteentre o genérico e o particular. Piracicaba: UNIMEP.

Scabini, E. (2000). Parent-child relationsihps in italian families: connectedness and autonomy in the transition to adulthood. Psicologia: Teoria e Pesquisa, 16 (1), 23-30.

Sennett, R. (1975). Vida urbana e identidad personal: los usos del desorden. Barcelona: Península.

Simmel, G. (1986). Sociologia: estudio sobre las formas de socialización (5a ed.). Madrid: Alianza.

Tajfel, H. (1984). Grupos humanos y categorias sociales: estudios de psicología social. Barcelona: Herder.

Torregrosa; J.R.E, \& Fernandez Villanueva, C. (1984). La interiorización de la estructura social. In J.R. Torregrosa \& E. Crespo. Estudios básicos de psicología social (pp. 234-82). Barcelona: Hora.

Vygotsky, L.S. (1993). Pensamento e linguagem. São Paulo: Martins Fontes.

Wallon, H. (1968). A evolução psicológica da criança. Lisboa: Edições 70.

Recebido para publicação em 1 de abril de 2004 e aceito em 18 de fevereiro de 2005 
